\title{
The Effects of Visual Feedback Self Exercise on Postural Control in Stroke Patients
}

\author{
Seong-Soo Hwang, PT, $\mathrm{PhD}^{\dagger} \cdot$ Je-Hyeok Lee, PT, $\mathrm{PhD}^{1} \cdot$ Yul-Jung Choi, PT, $\mathrm{MS}^{2}$ \\ Dept. of Physical Therapy, Shingu College, \\ ${ }^{1}$ Rusk Hospital, ${ }^{2}$ Roi Hospital
}

Received: August 16, 2017 / Revised: October 13, 2017 / Accepted: November 1, 2017

(C) 2017 J Korean Soc Phys Med

\begin{abstract}
| Abstract |
PURPOSE: The purpose of this research was to know the effect of visual feedback self exercise (VFSE) on postural control in stroke patients.
\end{abstract}

METHODS: $26 \mathrm{CVA}$ patients were participated. The experimental group (EG) $12(46.2 \%)$ and the control group (CG) 14 (53.8\%), 17 males and 9 females. The subjects preformed VFSE on training instrument 10 minutes for 20 times in 2-3 weeks. The test was done 3 times.

RESULTS: There were no statistically significant differences of the general characteristics of subjects between EG and CG by sex, affected site, muscle tone, sensory deficit, unilateral neglects, and vestibular dysfunction. The postural control effects of VFSE, in the EG showed that there were statistically significant differences among the tests during VFSE. However in the CG there were no statistically significant differences among the tests during VFSE. Also there was statistically significant difference between EG and CG after VFSE $(p<.05)$. On the right hemiplegic EG showed that there was statistically significant difference between pre-

$\dagger$ Corresponding Author : sshwang117@gmail.com

This is an Open Access article distributed under the terms of the Creative Commons Attribution Non-Commercial License (http://creativecommons.org/licenses/by-nc/3.0) which permits unrestricted non-commercial use, distribution, and reproduction in any medium, provided the original work is properly cited. mid test and pre-post test after VFSE. But, the left hemiplegic EG showed that there was no statistically significant difference between before and after VFSE with all of tests. CONCLUSION: CVA patients had significant different of body weight ratio between hemiplegic side and the other side. This research suggested that CVA patients need self exercise with visual feedback for the improvement postural control ability. Therefore Physical therapist should not only prescribe hand-on exercise but also need to teach them self sensory feedback exercise to help them improve their postural control.

Key Words: CVA, Exercise, Visual feedback, Weight-bearing

\section{Introduction}

Stroke patients has local brain lesion caused by cerebrovascular circulation problem such as hemorrhage or infarction. Therefore the stroke patients have to live with permanent neurologic dysfunction for their whole lives after onset. Physical therapy helps to improve the functional mobility in their daily lives. During physical therapy, stroke patients must improve their daily living activity by themselves independently. Also one of aims of physical therapy is to develop the ADL independency of stroke 
patients. Independent walking is one of main problem of stroke patient. Many patients have uneven weight bearing ratio on legs during standing and walking, so they need training to learn how to bear more weight bearing to hemiplegic leg (Moon et al., 2014; Kwon and Hwang, 2009). Furthermore they have no ideas how much weight they are bearing on each leg. One of program to improving standing balance was to use their visual sensory feedback (Franz et al., 2015; Goodworth et al., 2015).

Therefore the purpose of this research was to investigate the effect of visual feedback self exercise on stroke patients, to see if they can give even weight bearing on both legs by themselves after visual feedback self exercise. The detailed purposes of this study were as following.

First: To analyze postural control characteristics of CVA patients in standing position.

Second: To analyze the effects in postural control after visual feedback self exercise.

Third: To analyze postural control effects of visual feedback self exercise on hemiplegic side.

\section{Methods}

\section{Subject}

There were 26 CVA patients who agreed to participate in this research. All subjects of this study were in-patients of the rehabilitation hospital. The subjects were divided into two groups, one was experimental $(n=12)$ group and the other one was control group $(n=14)$. The gender of subjects was female $9(35 \%)$ and male $17(65 \%)$.

\section{Measurement of Body Weight Bearing Ratio}

As for the measurement weight bearing ratio on each leg, two body weight scales were used to measure it, the instruments of body weight scale were made by CAS company and model number was HE-65. The body weight ratios of all subjects were measured for three times on both legs and the mean score was calculated.

\section{Visual Feedback Self Exercise Instrument}

For the visual feedback self exercise, it was designed by Hwang Seongsoo was made by Apsun medical company in South Korea, it was called visual feedback self exercise (VFSE) Instrument (Fig. 1). This VFSE instrument consists of three components: monitor, footplate and safety bar. The monitor has three viewers and two color signal viewer, the three viewers show two legs weight bearing scale and total weight scale with number, two color signal viewer showed body weight leaning grade on each leg, the red color means less weight bearing and blue color means more weight bearing. When the subject was standing on this instrument, they can read how much weight scale on each of their legs and simultaneous they can see the color signal which leg bears more weight.
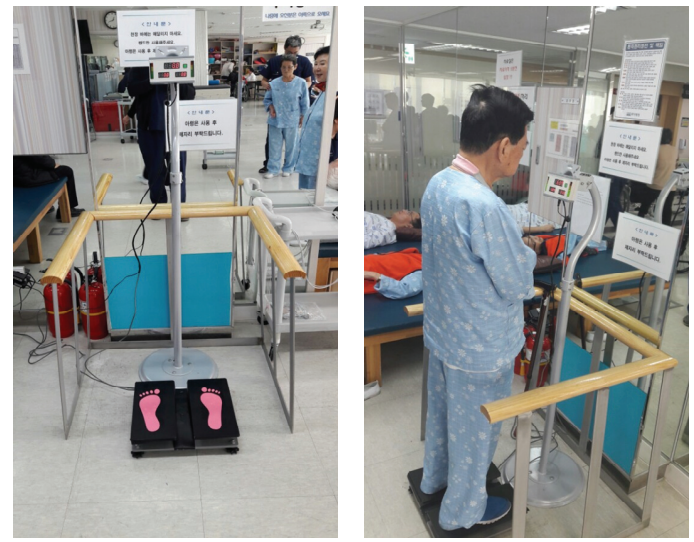

Fig. 1. Visual feedback self exercise (VFSE) Instrument

\section{Visual Feedback Self Exercise}

Visual feedback self exercise is that the CVA patients is doing exercise with visual sensory feedback by himself without any instructions and helper. When the subjects were standing on VFSE instrument and they could read the scale the difference of his/her own body weights on each legs by themselves. Also the subjects could see the color signal which leg lean more weight bearing. And then the subjects try to shift their bodies to left or to right, to match the color and number of scale $50 \%$ and $50 \%$ on both legs. 
The goal of this exercise the patients was that the patients bear $50 \%$ of their body weight on both legs. After learning it, then the patients can do this by themselves automatically.

The experimental group would do 2 times visual feedback self exercise a day for 10 minutes in the morning and afternoon during their regular treatment program. The experimental group performed totally 20 sessions visual feedback self exercise for 3 weeks.

\section{Procedure}

All subjects, experimental and controlled group, tested the difference of weight bearing ratio of both leg in standing position. The difference of body weight bearing ratio on each leg measured 3 times and calculated mean score. All subjects were in-patients, so the experimental group and control group took therapeutic exercise with their regularly treatment program from Monday to Saturday. The experimental group performed their regularly therapeutic exercise program with visual feedback self exercise. It means experimental group and control group took same time intervention. Control group performed regularly therapeutic exercise program. Experimental group performed 20 sessions visual feedback self exercise during 2-3 weeks. Finally, after 20 sessions of visual feedback self exercise, the weight bearing ratio of all subjects were tested again in the same way as before. Tests were done 3 times, pre-test (before exercise), mid-test (after 10 sessions exercise), and post-test (after 20 sessions exercise).

\section{Results}

\section{The General Characteristics of Subjects}

The general characteristics of subjects of this study were analyzed by gender, affected body side, degree of muscle tone, sensory deficit, unilateral neglects, and vestibular dysfunction (Table 1). The number of experimental group was $12(46.6 \%)$ and control group was $14(53.4 \%)$. There was no statistically significant difference between experimental and control group in all variables.

And the mean difference of weight bearing ratio on both legs of experimental group was $12.43 \mathrm{~kg}$ and control group was $18.42 \mathrm{~kg}$. There was no statistically significant difference between experimental and control group of difference of weight bearing ratio on both legs.

\section{The Postural Control Effects of Visual Feedback} Self Exercise

The effects of postural control during visual feedback self exercise were analyzed and the difference of weight bearing ratio on both legs in experimental and control group were recoded (Table 2) (Fig. 2).

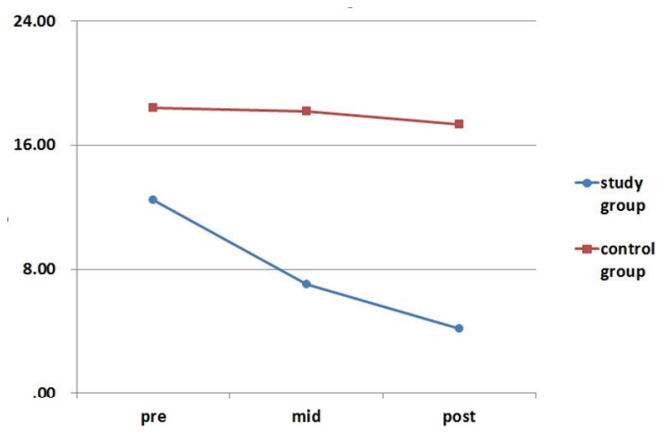

Fig. 2. The postural control effects during visual feedback self exercise on both groups

In the experimental group, there were statistically significant differences among before (mean difference $12.43 \mathrm{~kg}$ ), mid (mean difference $7.01 \mathrm{~kg}$ ) and after (mean difference $4.19 \mathrm{~kg}$ ) visual feedback self exercise. But in the control group there were no statistically significant difference among before (mean difference $18.42 \mathrm{~kg}$ ), mid (mean difference $18.21 \mathrm{~kg}$ ) and after (mean difference $17.36 \mathrm{~kg}$ ) visual feedback self exercise.

Also there were statistically significant difference between experimental and control group on the effects of postural control during visual feedback self exercise $(\mathrm{p}<.05)$. 
108 | J Korean Soc Phys Med Vol. 12, No. 4

Table 1. The general characteristics of the subjects $(\mathrm{N}=26)$

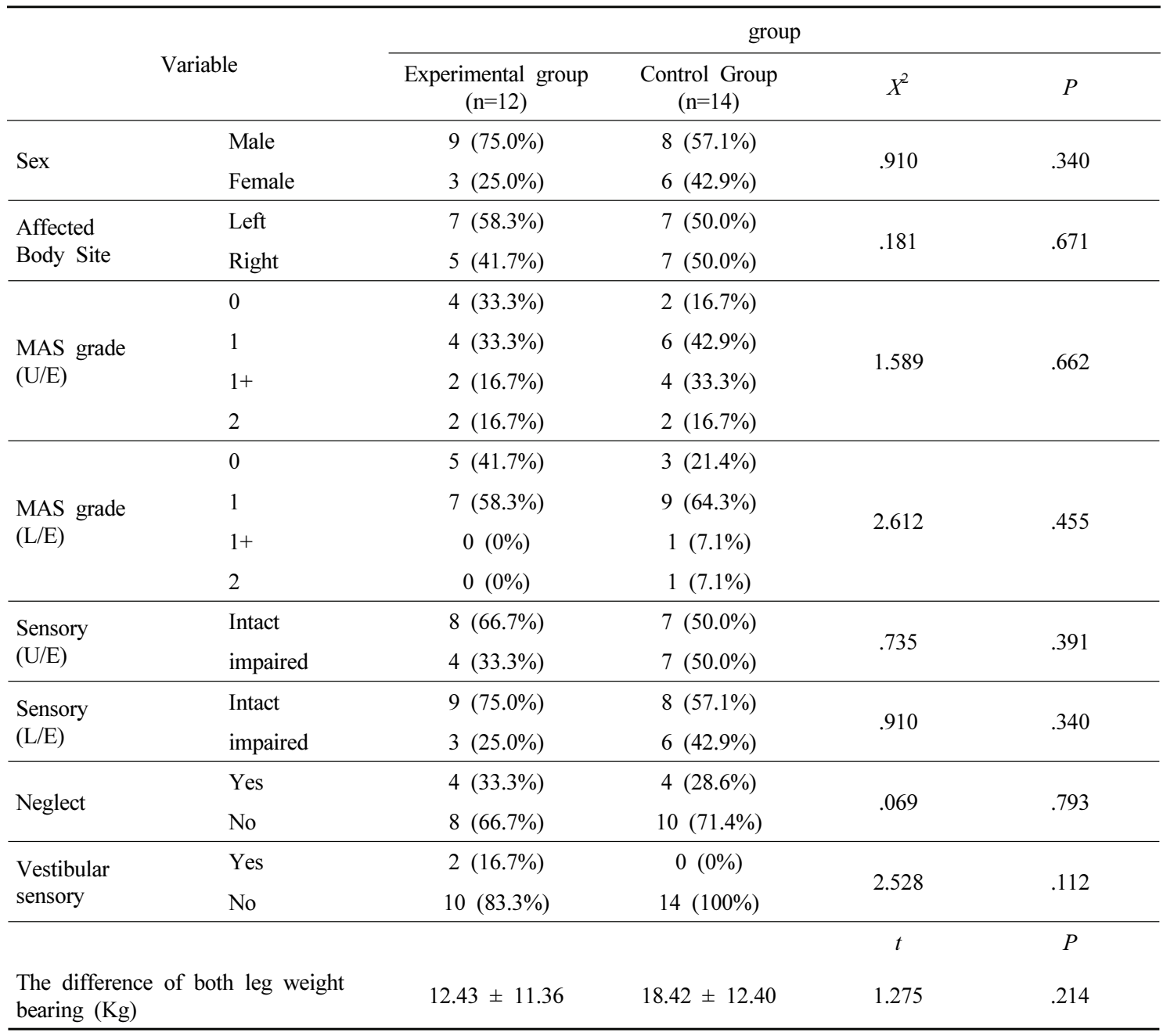

Values are $\mathrm{N}(\%)$ or Mean \pm standard deviation, ns: not significant,

General characteristics and dependent variables were calculated by Chi-squared test and Independent t-test

Table 2. The postural control effects during visual feedback self exercise on both groups

\begin{tabular}{|c|c|c|c|c|c|}
\hline \multirow{2}{*}{\multicolumn{2}{|c|}{$\begin{array}{l}\text { Group } \\
\text { Variable }\end{array}$}} & $\begin{array}{l}\text { Experimental Group } \\
\qquad(\mathrm{n}=12)\end{array}$ & $\begin{array}{l}\text { Control group } \\
(n=14)\end{array}$ & \multirow[t]{2}{*}{$\mathrm{F}$} & \multirow[t]{2}{*}{$P$} \\
\hline & & Mean \pm SD & Mean \pm SD & & \\
\hline The difference & Pre & $12.43 \pm 11.36$ & $18.42 \pm 12.40$ & \multirow{4}{*}{6.922} & \multirow{4}{*}{$.002 *$} \\
\hline $\begin{array}{l}\text { of weight } \\
\text { bearing }\end{array}$ & Mid & $7.01 \pm 8.69$ & $18.21 \pm 12.99$ & & \\
\hline \multirow{2}{*}{$\begin{array}{l}\text { ratio on both } \\
\text { legs }\end{array}$} & Post & $4.19 \pm 17.36$ & $17.36 \pm 11.85$ & & \\
\hline & $P$ & $.001 *$ & .452 & & \\
\hline
\end{tabular}


The postural control effects of visual feedback self exercise were analyzed, the difference of body weight bearing ratio on both legs with pre and mid test, mid and post test, and pre and post test on each group were recoded (Table 3).

In the experimental group, there were statistically significant differences between pre test and mid test $(\mathrm{p}<.05)$, and pre test and post test $(\mathrm{p}<.05)$. There was no statistically significant difference between mid test and post test $(\mathrm{p}>.05)$.
In the control group, there was no statistically significant difference between all tests.

\section{The Postural Control Effects of Visual Feedback} Self Exercise in Experimental Group by Hemiplegic Side

The postural control effects of visual feedback self exercise were analyzed and the difference of weight bearing on both legs by hemiplegic site in experimental group were recoded (Table 4).

Table 3. The effects of visual feedback self exercise between pre, mid and post test on each group

\begin{tabular}{|c|c|c|c|c|}
\hline \multirow[b]{2}{*}{ Variable } & \multicolumn{4}{|c|}{ Group } \\
\hline & $\begin{array}{l}\text { Experimental group } \\
\qquad(n=12)\end{array}$ & $\mathrm{P}$ value & $\begin{array}{l}\text { Control group } \\
\qquad(\mathrm{n}=14)\end{array}$ & $\begin{array}{c}\mathrm{P} \\
(t \text {-value })\end{array}$ \\
\hline \multirow{3}{*}{$\begin{array}{l}\text { The Difference of weight } \\
\text { bearing on both legs }\end{array}$} & Pre test - Mid test & $\begin{array}{l}2.282 \\
\left(.017^{*}\right)\end{array}$ & Pre test - Mid test & $\begin{array}{l}.275 \\
(.788)\end{array}$ \\
\hline & Mid test - Post test & $\begin{array}{l}2.025 \\
(.068)\end{array}$ & Mid test - Post test & $\begin{array}{l}.776 \\
(.452)\end{array}$ \\
\hline & Pre test - Post test & $\begin{array}{l}3.599 \\
(.004 *)\end{array}$ & Pre test - Post test & $\begin{array}{l}1.483 \\
(.162)\end{array}$ \\
\hline
\end{tabular}

${ }^{*} p<.05$

Table 4. The comparison of Left and Right hemiplegic after Visual feedback self exercise on experimental group

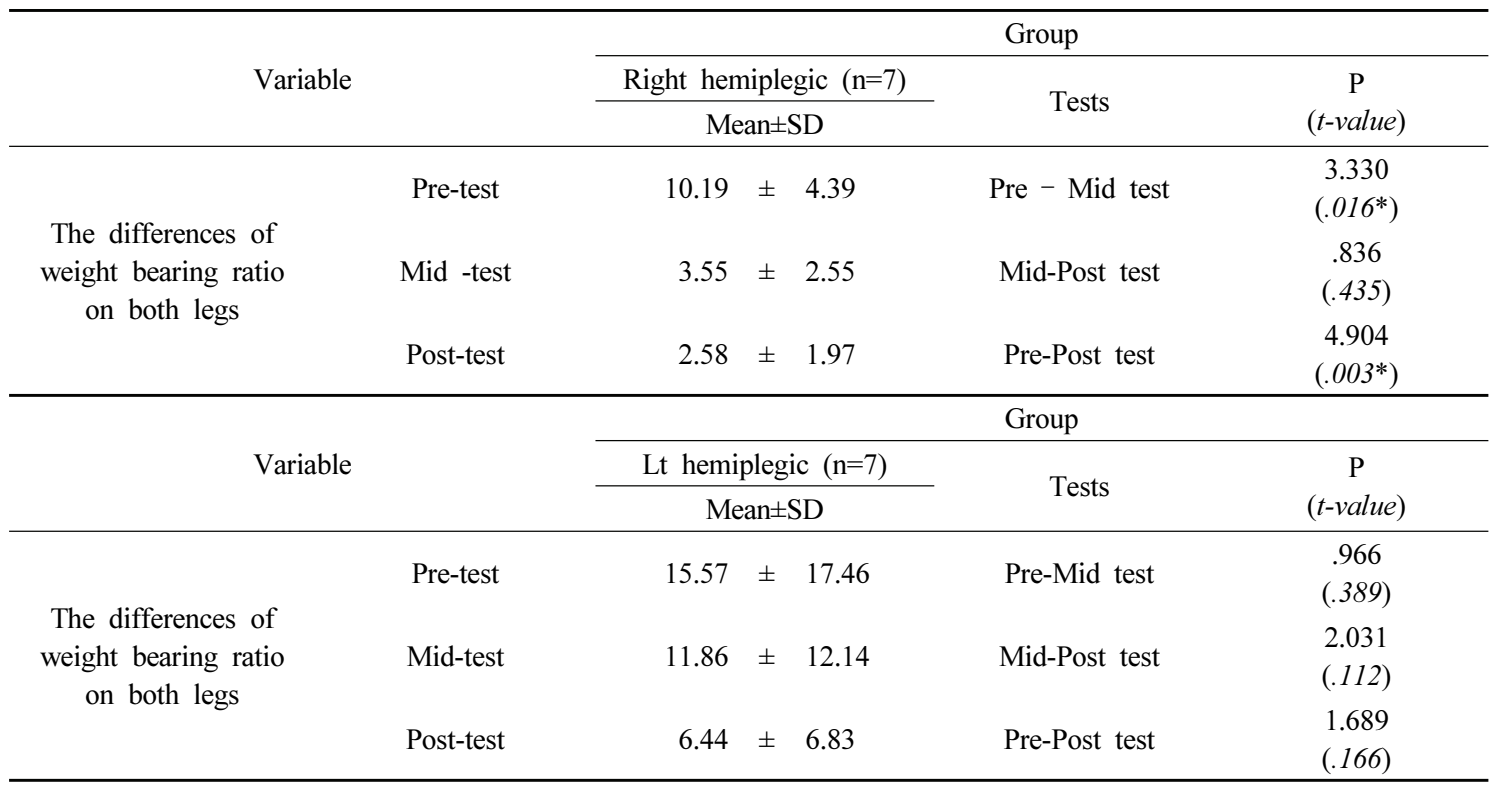

${ }^{*} p<.05$ 
The difference of weight bearing ratio on both legs was compared with Left and Right hemiplegic side after Visual feedback self exercise in experimental group.

On the right hemiplegic experimental group showed that there were statistically significant differences between pre and mid test, and pre and post-tests after visual feedback self exercise. But there was no significant difference between mid and post-tests after visual feedback self exercise.

On the left hemiplegic experimental group there was no statistically significant difference between before and after visual feedback self exercise with all of tests.

\section{Discussion}

There were so many various researches for improving standing balance on CVA patients. Also each research designed with different training time and periods. As for the exercise time of one session, some was 15minutes (Kim and Cha, 2015), 30minutes (Lee et al., 2015), and 40 minutes (Yun and Yoo, 2016) in different studies. Also in some studies, the training period was designed for 4weeks (Kim and Cha, 2015; Lee et al., 2015), and 5weeks (Van Den Heuvel et al., 2016). In this study the subjects performed 10 minutes for 3 weeks. This study suggested visual feedback self exercise could get the postural control effects in a short time and short period treatment.

As for the design of visual feedback exercise, there were 2 ways. One was well-designed PC program and the other was controlled by their body movement with monitoring. Van Den Heuvel et al. (2016) used workstation which consisted of a flat-panel LCD monitor connected to a PC containing a total of six, commercially available, interactive balance exercise. After visual feedback exercise, there was statistically significant different between pre and post training on non-preferred single leg and $10 \mathrm{~m}$ walking speed test. But this study, self control exercise program by their own variation of weight bearing balance was designed. So visual feedback self exercise is better results than mechanical weight bearing balance exercise. Bartur et al. (2016) used mirror for visual feedback training, Kennedy et al. (2016) designed visual exercise by visually guided mediolateral weight shifting. Walkera et al. (2016) were designed different types of visual feedback during treadmill walking. These different types of visual feedback were different visual field, moving laser circle, and moving target with laser. O'brien et al. (2017) designed to give feedback for lateral weight shifting with WeHab system. Sayenko et al. (2012) used visual feedback external mechanically unperturbation for postural corrective responses

As for the subjects of visual sensory feedback training, there were applied various types of patients, they were mainly CVA (Rah et al., 2006; Choi, 2009; Kuk, 2010; Kim and Cha, 2015; Lee et al., 2015; Shim, 2016; Walkera et al., 2016) and spinal cord injury (Sayenko et al., 2010), Parkinson (Van Den Heuvel et al., 2016), cerebral palsy (Yun and Yoo, 2016).

As for the training program for CVA, Bang and Cho (2017b) analyzed for standing balance after arm training on standing position. The results of their study showed that the improvement on all outcomes such as Berg balance test and walking ability of pre to post tests. This result mean that the standing balance also can improve by doing arm exercise. Bang and Cho (2017a) designed postural control training in various different position for standing balance and walking on CVA patients. Yun and Yoo (2016) researched with visual biofeedback training for functional ability. Jang and Kim (2016) reported the effects of trunk control exercise for dynamic balance on stroke patients. Subjects received physical therapy for 15 minutes in each session and balance training was performed for 20 minutes on three-dimensional balance trainers.

Moon et al. (2012) designed different training program compare with this study. They trained for gait with and without deprivation visual cue and they reported deprivation 
visual cue training group show better results of maximum gait speed, functional gait assessment, comfortable gait speed. This result seemed that visual cue deprivation also give information to the sensory feedback system. Kim and Cha (2015) used weight shifting training with electrical sensory stimulation feedback 15 minutes for 4 weeks. Lee et al. (2015) reported visual feedback and auditory feedback training could improve on standing balance performance of CVA.

\section{Conclusion}

This research investigated the effect of visual feedback self exercise on postural control in stroke patients. The subjects were preformed visual feedback self exercise on training instrument. First the CVA patients had the difference of body weight bearing ratio on both legs by gender, affected body side, degree of muscle tone, sensory deficit, unilateral neglects, and vestibular dysfunction. Second, this visual feedback self exercise showed the effects of postural control after 2 weeks training. Third the visual feedback self exercise could improve more right hemiplegic CVA patient's standing postural control capacity than left hemiplegic CVA group. This research suggested that CVA patients needs self exercise with sensory visual feedback for the improvement their postural control ability. Therefore Physical therapist should design exercise program not only hand-on exercise but also self sensory feedback exercise to the Stroke patients.

\section{Acknowledgements}

This study was supported by a 2016 faculty research grant from Shingu College, South Korea.

\section{References}

Bang DH, Cho HS. The effect of postural control training on balance and walking ability in patients with chronic stroke. J Korean Soc Phys Med. 2017a;12(2):59-66.

Bang DH, Cho HS. The effect of arm training in standing position on balance and walking ability in patients with chronic stroke. J Korean Soc Phys Med. 2017b;12(2):75-82.

Bartur G, Pratt H, Dickstein R, et al. Electrophysiological manifestations of mirror visual feedback during manual movement. Brain Res. 2016;1606:113-24.

Choi YJ. The effects of body weight bearing treadmill with visual feedback on the gait of stroke patients. Master's Degree. DanKook University. 2009.

Franz JR, Francis CA, Allen MS, et al. Advanced age brings a greater reliance on visual feedback to maintain balance during walking. Hum Mov Sci. 2015;40: 381-92.

Goodworth A, Perrone K, Pillsbury M, et al. Effects of visual focus and gait speed on walking balance in the frontal plane. Hum Mov Sci. 2015;42:15-26.

Jang JY, Kim SY. Effects of trunk control exercise performed on an unstable surface on dynamic balance in chronic stroke patients. J Korean Soc Phys Med. 2016; 11(1):1-9.

Kennedy MW, Crowell CR, Villano M, et al. Effects of filtering the center of pressure feedback provided in visually guided mediolateral weight shifting. PLoS ONE 2016;11(3):1-17.

Kim DY, Cha YJ. Effect of weight shift training with electrical sensory stimulation feedback on standing balance in stroke patients. J Korean Soc Phys Med. 2015; 10(3):257-63.

Kuk JS. The effect of balance with visual cue deprivation and visual feedback training in stroke patient. Master's Degree. Daegu University. 2010.

Kwon HJ, Hwang SS. The characteristics of weight bearing 
ratio on different position of ages group. KAOMPT. 2009;15(1):9-21.

Lee DH, Choi SJ, Choi HS, et al. Comparison of visual and auditory biofeedback during sit-to-stand training for performance and balance in chronic stroke patients. J Korean Soc Phys Med. 2015;10(4):59-68.

Moon SJ, Kim YW, Kim TH. The effects of balance training with visual cue deprivation on gait function in patients with stroke. J Korean Soc Phys Med. 2012;7(4): 411-21.

Moon Y, Kim MS, Choi JD. Correlation between weight bearing ratio and functional level for development of pressure sensor biofeedback in stroke patients. J Korean Soc Phys Med. 2014;9(3):315-24.

O'Brien K, Crowell CR, Schmiedeler J. Error augmentation feedback for lateral weight shifting. Gait Posture. 2017;54:178-82.

Rah YH, Goo BO, Rho MH, et al. The effect of external feedback weight-bearing training protecting a fall in hemiplegic patients. J Korean Soc Phys Med. 2007;2(2):143-150.

Sayenko DG, Alekhina MI, Masani K, et al. Positive effect of balance training with visual feedback on standing balance abilities in people with incomplete spinal cord injury. Spinal Cord. 2010;48:886-93.

Sayenko DG, Masani K, Vette AH, et al. Effects of balance training with visual feedback during mechanically unperturbed standing on postural corrective responses. Gait Posture. 2012;35:339-44.

Shim SY. The effects of visual feedback step exercise on anticipatory postural adjustment, balance and cognition of chronic stroke patient. Master's Degree. Sahmyook University. 2016.

Van Den Heuvel MRC, Daffertshofer A, Beek PJ, et al. The effects of visual feedbakc during a rhythmic weightshifting task in patients with Parkinson's disease. Gait Posture. 2016;48:140-5.

Walkera ER, Hyngstrom AS, Schmit BD. Influence of visual feedback on dynamic balance control in chronic stroke survivors. J Biomech. 2016;49(5):698-703.

Yun CK, Yoo JN. The effect of visual biofeedback balance training on functional ability in children with cerebral palsy : a pilot study. J Korean Soc Phys Med. 2016; 11(3):133-9. 